\title{
PERBEDAAN TINGKAT KECEMASAN IBU BERSALIN DI PUSKESMAS DENGAN DI BIDAN PRAKTIK MANDIRI
}

\author{
Fatihatul Hayati \\ Program Studi D3 Kebidanan STIKes Baiturrahim Jambi \\ Email: fatihatulhayatianam@gmail.com
}

\begin{abstract}
Maternal mortality rate is higher in assisted childbirth rather than that of natural childbirth. The unresolved anxiety can cause childbirth to last longer and lead to assisted childbirth. Childbirth environment at the hospital can increase maternal anxiety which results in disturbing uterine contraction so that action should be taken to speed up the delivery process. The aim of this study was to determine the difference in anxiety level between mothers who give birth at the Public Health Center and those who give birth at Private Midwife Center. The study was conducted by cross-sectional design on 74 mothers in labor. They were divided into two groups: those who give birth at Public Health Center and those who give birth at Private Midwife Center with consecutive sampling technique.Data were then analyzed by conducting Independent $T$ test. The result showed that the first group had higher average score of anxiety than the second group with $p$ value $<0.05$.The study suggested that there was significant difference between giving birth at Public Health Center and giving birth of Private Midwife Center
\end{abstract}

Keywords : Anxiety Level, Period of Labor

\begin{abstract}
ABSTRAK
Kejadian kematian ibu lebih tinggi terjadi pada ibu yang bersalin dengan tindakan dibandingkan pada ibu yang bersalin normal. Rasa cemas yang tidak teratasi juga dapat menyebabkan persalinan berlangsung lebih lama dan harus diakhiri dengan tindakan. Lingkungan bersalin di rumah sakit dapat meningkatkan kecemasan ibu yang berakibat mengganggu kontraksi uterus sehingga tindakan harus dilakukan untuk mempercepat proses persalinan. Tujuan penelitian untuk mengetahui perbedaan tingkat kecemasan ibu bersalin di Puskesmas dengan di Bidan Praktik Mandiri. Desain penelitian adalah crossectional terhadap 74 orang ibu bersalin yang dibagi menjadi dua kelompok yaitu ibu bersalin di Puskesmas dan ibu bersalin di Bidan Praktik Mandiri (BPM) dengan teknik consecutive sampling.Data dianalisis dengan uji $\mathrm{T}$ independen dan hasilnya terdapat perbedaan signifikan dengan nilai $\mathrm{p}<0,05$. Kesimpulan, ada perbedaan signifikan antara tingkat kecemasan ibu bersalin di Puskesmas dengan di Bidan Praktik Mandiri.
\end{abstract}

Kata kunci: Tingkat Kecemasan, Lama Persalinan 


\section{PENDAHULUAN}

Indikator

keberhasilan pembangunan suatu negara dapat dilihat dari Angka Kematian Ibu (AKI), yang dipengaruhi oleh status kesehatan secara umum, pendidikan dan pelayanan kesehatan selama kehamilan dan melahirkan. AKI juga merupakan salah satu target yang telah ditentukan dalam Millenium Development Goals (MDGs) yang kelima, yaitu meningkatkan kesehatan ibu dimana target yang akan dicapai sampai tahun 2015 adalah mengurangi sampai $3 / 4$ resiko jumlah kematian ibu, yaitu 102 per 100.000 kelahiran hidup. ${ }^{1}$

Sasaran ibu bersalin di Kota Padang pada tahun 2012 adalah 18.457 dan melakukan persalinan dengan tenaga kesehatan $92,3 \%$ atau 17.027 ibu bersalin, angka ini sudah melebihi target (92\%), namun kasus kematian ibu di kota Padang tahun 2014 sebanyak 19 orang, meningkat dibandingkan tahun 2012 sebanyak 16 orang. ${ }^{2}$ Hasil penelitian memperlihatkan bahwa AKI lebih tinggi terjadi pada ibu yang cara persalinannya ditolong dengan tindakan dibandingkan ibu yang persalinannya berlangsung spontan. Kematian ibu tersebut disebabkan oleh perdarahan (32\%), eklampsia (14\%), partus lama (12\%), infeksi (11\%), abortus (14\%), penyakit jantung (5\%), dan lain-lain (12\%). Perdarahan ibu terjadi karena retensi plasenta, anemia berat, partus lama, dan lainnya. ${ }^{3}$

Penyebab kematian ibu ketiga di Sumatera Barat adalah partus lama, yaitu persalinan yang berlangsung lebih dari 24 jam. $^{2}$ Permasalahan harus dikenali dan diatasi sebelum batas waktu 24 jam tercapai. Sebagian besar partus lama menunjukkan perpanjangan kala I. Sebab utama dari partus lama adalah disproporsi feto pelvik, malpresentasi dan malposisi serta kerja uterus yang tidak efisien, termasuk serviks yang kaku. Sementara partus lama dapat mengakibatkan perdarahan pada ibu inpartu maupun postpartum. Disamping itu, pada bayi partus lama dapat pula menyebabkan terjadinya asfiksia, yang merupakan penyebab terbesar kematian bayi di Sumatera Barat. ${ }^{4}$

Salah satu faktor emosi atau psikologis terjadinya partus lama adalah ketakutan dan kecemasan ibu yang tidak teratasi selama melahirkan. ${ }^{5} 65 \%$ kejadian partus lama disebabkan karena kontraksi uterus yang tidak efisien sebagai respon terhadap kecemasan sehingga menghambat aktifitas uterus. ${ }^{6}$

Salah satu penyebab terjadinya partus lama adalah respon stres, dan ini menempati urutan paling atas di antara penyebab-penyebab yang lainnya. Kondisi ini terjadi karena ibu bersalin akan menghadapi berbagai masalah dalam adaptasinya selama proses persalinan, diantaranya rasa nyeri saat kontraksi, ketakutan akan ketidakmampuan dalam menangani masalah yang akan terjadi, ketegangan dan hiperventilasi. ${ }^{7}$

Sekitar $6 \%$ dari populasi umum mengalami gangguan cemas, generalized anxiety disorder (GAD) merupakan gangguan yang paling sering ditemui, terjadi pada $2-4 \%$ populasi. $^{8}$ Permasalahan psikologis yang dialami ibu bersalin dalam menghadapi persalinan yaitu cemas (52\%) dan ragu akan kemampuannya mengatasi rasa nyeri (43\%). ${ }^{9}$ Kecemasan dan ketakutan yang dialami oleh ibu bersalin terutama primipara dapat memperpanjang durasi persalinan dan meningkatkan kejadian persalinan dengan tindakan, yaitu persalinan dengan seksio sesarea (OR 26,9 CI 95\%) dan vakum ekstraksi (OR 4,5 CI 95\%). Ibu yang pernah melahirkan dan mengalami cemas pada saat melahirkan merupakan saat-saat tidak menyenangkan dalam hidupnya. ${ }^{6}$

Kecemasan yang tidak teratasi juga merupakan prediktor terjadinya nyeri selama melahirkan yang akan mempengaruhi kesehatan ibu dan bayi. Sebaliknya nyeri selama melahirkan juga menyebabkan timbulnya kecemasan, sehingga antara stres, 
kecemasan, ketakutan dan nyeri merupakan siklus yang berkesinambungan. ${ }^{10}$ Sementara pasien yang mengalami nyeri empat kali lebih cemas dibandingkan dengan pasien yang tidak mengalami nyeri. ${ }^{11}$

Fenomena yang berkembang selama ini para petugas kesehatan baik dokter, bidan, maupun perawat kebanyakan hanya memperhatikan kondisi fisik dibandingkan dengan pemenuhan kebutuhan kondisi psikis dari ibu dalam menjelang persalinan dan selama persalinan. Kondisi ini dapat memicu terjadinya kecemasan dan rasa takut pada ibu yang sedang melahirkan. ${ }^{12}$ Perbedaan waktu persalinan antara wanita yang mengalami ketakutan dengan yang tidak mengalami ketakutan adalah 1 jam 32 menit. ${ }^{13}$

Kecemasan bisa terjadi karena pengalaman baik pengalaman bersalin sebelumnya atau pengalaman buruk kerabat atau teman tentang persalinan dan kenyataan bahwa kehamilan yang beresiko juga menyebabkan ibu tidak siap menghadapi persalinan. Tenaga medis dan situasi tempat yang tidak bersahabat dapat mempengaruhi rasa nyaman ibu untuk melahirkan. ${ }^{14}$ Tindakan untuk mengupayakan rasa nyaman dapat berupa upaya menciptakan suasana yang nyaman dalam kamar bersalin, memberi sentuhan, memberi penanganan nyeri tanpa obat dan yang paling penting berada di sisi ibu. ${ }^{15}$

Pada jaman dahulu, perempuan belajar tentang persalinan dari ibu dan saudara perempuannya. Persalinan berlangsung di rumah dengan situasi yang familiar dengan mereka sehingga memberikan suasana yang nyaman dan mengurangi kecemasan. Selama proses persalinan, mereka akan ditemani oleh suami dan anggota keluarga lain yang diinginkannya, yang terus memberikan dukungan dan membesarkan hati mereka dalam menjalani proses tersebut. Pada masa itu bidan komunitas yang menolong hampir sebagian besar persalinan. ${ }^{16}$

Orientasi pelayanan kebidanan pada abad ke-dua puluh mengalami perubahan ke arah medikalisasi, maka pertolongan persalinan yang awalnya berlangsung di rumah dialihkan ke rumah sakit. Tentunya nilai-nilai yang dimiliki oleh perempuan sebelumnya tidak dapat diterapkan seluruhnya di rumah sakit. Para provider memberikan pelayanan dan dukungan namun tidak dapat secara utuh karena perhatian mereka terbagi karena begitu banyak klien yang menjadi tanggung jawabnya. ${ }^{16}$ Demikian juga dengan peran keluarga yang tidak optimal dalam persalinan di rumah sakit, karena keterbatasan ruang bersalin dan jumlah pasien bersalin.

Beberapa ibu bersalin merasa cemas di lingkungan rumah sakit dan kondisi ini dapat memperlambat kontraksi, membuat persalinan lebih lama dan tindakan terpaksa harus dilakukan untuk mempercepat proses persalinan. Ibu yang bersalin di rumah sakit mungkin juga tidak bisa mendapatkan perawatan dari bidan yang sesuai dengan keinginan selama proses persalinannya. Berbeda dengan persalinan di praktik bidan yang biasanya dirancang agar terlihat seperti rumah dengan perawatan dari seorang bidan yang sama. ${ }^{15}$

Teori lingkungan terapetik dapat mempengaruhi kenyamanan ibu bersalin selama proses persalinannya. Fasilitas pelayanan kesehatan untuk pasien diharapkan dapat meningkatkan kesehatan, keamanan, dan hubungan sosial yang normal dan tidak terkesan mengisolasi. Desain lingkungan yang terapetik diperlukan untuk pasien di lingkungan rumah sakit. ${ }^{17}$

Seorang wanita hamil berisiko rendah harus melahirkan di tempat yang membuat wanita merasa aman dan nyaman. Tempat tersebut harus merupakan sebuah tempat dimana semua perhatian dan perawatan difokuskan pada kebutuhan dan keamanannya, sedekat mungkin dengan 
lingkungan yang dikenalnya. Hal ini penting karena persalinan merupakan situasi yang penuh dengan kecemasan dan dipenuhi oleh pikiran negatif yang berakibat pada kestabilan emosi ibu bersalin, sehingga akan berpengaruh juga pada proses persalinan. ${ }^{18}$ Keberadaan suami dan keluarga serta dukungan lingkungan selama proses persalinan akan memberikan rasa aman serta dapat mengurangi rasa nyeri dan persalinan berlangsung lebih cepat. ${ }^{19}$

Studi pendahuluan yang dilakukan pada 10 orang ibu bersalin di Puskesmas dan 10 orang ibu bersalin di Bidan Praktik Mandiri (BPM), didapatkan hasil bahwa pada ibu bersalin di Puskesmas, 2 orang (20\%) mengalami kecemasan ringan, 4 orang (40\%) mengalami kecemasan sedang dan 4 orang $(40 \%)$ mengalami kecemasan berat, dengan lama persalinan 7 orang $(70 \%)$ normal dan 3 orang $(30 \%)$ memanjang. 2 orang ibu bersalin kala I memanjang dirujuk atas indikasi partus lama dan gawat janin. Sementara di BPM didapatkan ibu bersalin dengan tingkat kecemasan ringan 3 orang (30\%) dan ibu bersalin dengan tingkat kecemasan sedang 7 orang (70\%). Adapun lama persalinan kala I di BPM didapat bahwa 9 orang (90\%) normal dan 1 orang (10\%) memanjang.

\section{METODE PENELITIAN}

Penelitian ini bersifat analitik dengan rancangan cross sectional study comparative. Penelitian ini dilakukan di seluruh Puskesmas Perawatan di kota Padang dan empat Bidan Praktik Mandiri (BPM) Kota Padang yang ratarata persalinan perbulannya cukup banyak, bersedia dijadikan tempat penelitian dan lokasinya terjangkau. Baik Puskesmas maupun BPM menyediakan fasilitas Badan Penyelenggara Jaminan Sosial (BPJS) Kesehatan. Penelitian dilaksanakan November 2014-November 2015.
Sampel diambil dengan consecutive sampling terhadap 74 orang responden Ibu bersalin normal primigravida.

Data dianalisis dengan uji $\mathrm{T}$ independen untuk mengetahui perbedaan tingkat kecemasan ibu bersalin di Puskesmas dengan di Bidan Praktik Mandiri.

\section{HASIL DAN PEMBAHASAN}

Tabel 1. Gambaran Karakteristik Responden

\begin{tabular}{lccccc}
\hline Karakteristik & \multicolumn{2}{l}{ Puskesmas } & BPM & \\
\cline { 2 - 6 } Responden & $\mathrm{f}$ & $\%$ & $\mathrm{f}$ & $\%$ & \\
\hline Umur & & & & & 0,19 \\
\hline$<20$ Tahun & 13 & 35,1 & 7 & 18,9 & \\
20-35 Tahun & 24 & 64,9 & 30 & 81,1 & \\
\hline Pendidikan & & & & & 0,416 \\
\hline Menengah & 30 & 81,1 & 26 & 70,3 & \\
Tinggi & 7 & 18,9 & 11 & 29,7 & \\
\hline Pekerjaan & & & & & 0,752 \\
\hline Bekerja & 5 & 13,5 & 7 & 18,9 & \\
Tidak & 32 & 86,5 & 30 & 81,1 & \\
\hline Penghasilan & & & & & 1,000 \\
\hline$<$ UMR & 7 & 18,9 & 6 & 16,2 & \\
$\geq$ UMR & 30 & 81,1 & 31 & 83,8 & \\
\hline Suku & & & & & 1,000 \\
\hline Matrilineal & 30 & 81,1 & 30 & 81,1 & \\
Patrilineal & 7 & 18,9 & 7 & 18,9 & \\
\hline Lama & & & & & 0,100 \\
Menikah & & & & & \\
\hline$<1$ Tahun & 25 & 67,6 & 17 & 45,9 & \\
$\geq 1$ Tahun & 12 & 32,4 & 20 & 54,1 & \\
\hline Frekuensi & & & & & 1,000 \\
ANC & & & & & \\
\hline$<4$ Kali & 7 & 18,9 & 8 & 21,6 & \\
< 4 Kali & 30 & 81,1 & 29 & 78,4 & \\
\hline Senam & & & & & 1,000 \\
Hamil & & & & & \\
\hline Pernah & 12 & 32,4 & 13 & 35,1 & \\
Tidak & 25 & 67,6 & 24 & 64,9 & \\
Pernah & & & & & \\
\hline & & & & & \\
\hline
\end{tabular}

Tabel2.Perbedaan Dukungan Emosional yang Diberikan Kepada Ibu Bersalin di Puskesmas dengan di Bidan Praktik Mandiri

\begin{tabular}{llllll}
\hline Dukungan & \multicolumn{2}{l}{ Puskesmas } & \multicolumn{2}{l}{ BPM } & \multirow{2}{*}{$P$} \\
\cline { 2 - 5 } Emosional & f & $\%$ & f & $\%$ & \\
\hline Baik & 3 & 8,1 & 19 & 51,4 & 0,001 \\
\hline
\end{tabular}




\begin{tabular}{lrrrr}
$\begin{array}{l}\text { Kurang } \\
\text { Baik }\end{array}$ & 34 & 91,9 & 18 & 48,6 \\
\hline Jumlah & 37 & 100 & 37 & 100 \\
\hline
\end{tabular}

Tabel3.Hubungan Dukungan Emosional yang diberikan Kepada Ibu Bersalin dengan Tingkat Kecemasan

\begin{tabular}{|c|c|c|c|c|c|c|}
\hline Dukungan & & igan & & ang & \multicolumn{2}{|c|}{ Berat } \\
\hline Emosional & $\mathrm{f}$ & $\%$ & $\mathrm{f}$ & $\%$ & $\mathrm{f}$ & $\%$ \\
\hline Baik & 1 & 43,9 & 1 & 7,1 & 3 & 15 , \\
\hline $\begin{array}{l}\text { Kurang } \\
\text { Baik }\end{array}$ & 2 & 56,1 & 1 & 92 , & 1 & 84 , \\
\hline Jumlah & & 100 & & 10 & 1 & 10 \\
\hline
\end{tabular}

Tabel 4 Perbedaan Tingkat KecemasanIbuBersalin di Puskesmasdengan di BPM

\begin{tabular}{lccccc}
$\begin{array}{l}\text { Tempat } \\
\text { Persalinan }\end{array}$ & Mean & SD & SE & N & $P$ \\
\hline Puskesmas & 23,7 & 8,76 & 1,440 & 37 & \\
BPM & 17,76 & 8,62 & 1,417 & 37 & \\
\hline
\end{tabular}

Hasil penelitian menggambarkan bahwa rata-rata tingkat kecemasan ibu bersalin di Puskesmas lebih tinggi dibandingkan dengan tingkat kecemasan ibu bersalin di Bidan Praktik Mandiri (BPM).

Berdasarkan uji statistik didapat nilai $p<0,05$, maka disimpulkan bahwa ada perbedaan tingkat kecemasan ibu bersalin di Puskesmas dengan di Bidan Praktik Mandiri (BPM).

Perbedaan tingkat kecemasan dalam penelitian ini dikarenakan adanya perbedaan dukungan emosional yang ibu dapatkan selama persalinan dan terdapat hubungan antara dukungan emosional yang didapatkan ibu selama persalinan dengan tingkat kecemasan ibu bersalin. Pendamping persalinan sangat dibutuhkan oleh ibu bersalin. pendamping tersebut dapat berperan dengan cara memberikan sentuhan, hiburan dan dorongan untuk mendukung ibu saat proses persalinan. ${ }^{21}$ Pendamping ibu saat proses persalinan sebaiknya adalah orang yang peduli pada ibu dan yang paling penting adalah orang yang diinginkan ibu untuk mendampingi ibu selama proses persalinan. ${ }^{22}$

Salah satu penyebab tingginya AKI $P$ secara umum yaitu kurangnya perhatian dari keluarga, khususnya peran serta suami dalam proses kehamilan dan persalinan. Padahal suami sangat

0,0detperan dalam memberikan dukungan untuk membantu menenangkan kondisi fisik maupun psikis seorang istri. ${ }^{23}$

Dukungan yang membawa dampak positif adalah dukungan yang bersifat fisik dan emosional. Dukungan tersebut meliputi beberapa aspek seperti menggosok punggung ibu, memegang tangannya, mempertahankan kontak mata, ibu ditemani oleh orang-orang yang ramah, dan ibu tidak menjalani proses persalinan sendirian. ${ }^{21}$

Studi lain tentang sentuhan persalinan membuktikan bahwa dengan sentuhan persalinan $56 \%$ lebih sedikit yang mengalami tindakan Seksio Sesarea, pengurangan penggunaan anestesi epidural hingga 85\%, $70 \%$ lebihsedikit kelahiran dibantu forceps, $61 \%$ penurunan dalam penggunaan oksitosin, durasi persalinan yang lebih pendek $25 \%$ dan risiko komplikasi pada neonatus menurun $58 \%{ }^{16}$

Sentuhan dalam persalinan dapat mengurangi kecemasan, mengurangi nyeri dan meningkatkan kenyamanan, mengalami waktu persalinan secara signifikan lebih pendek, tinggal di rumah sakit lebih singkat dan kejadian depresi postpartum lebih rendah. Touch Research Institute juga melaporkan bahwa wanita yang dipijat pasangannya merasa kurang tertekan, mengalami nyeri persalinan yang kurang dan memiliki stres dan tingkat kecemasan yang lebih rendah. Selain itu, ibu yang dipijat ringan mengalami waktu persalinan secara signifikan lebih pendek, tinggal di rumah sakit lebih singkat dan depresi postpartum kurang. ${ }^{6}$ 


\section{SIMPULAN}

Tingkat kecemasan ibu bersalin di Puskesmas dalam kategori cemas sedang dan tingkat kecemasan ibu bersalin di Bidan Praktik Mandiri dalam kategori cemas ringan.Terdapat perbedaan tingkat kecemasan pada ibu bersalin di Puskesmas dan di Bidan Praktik Mandiri (BPM)

\section{SARAN}

1. Bagi penyedia pelayanan kebidanan agar dapat memfasilitasi kenyamanan psikologis ibu bersalin baik secara fisik maupun asuhan yang diberikan oleh tim medis dan paramedis serta melakukan evaluasi yang berkesinambungan sehingga pelayanan yang optimal dapat ditingkatkan.

2. Bagi penolong persalinan agar dapat senantiasa memperhatikan aspek psikologis ibu bersalin disamping memantau kemajuan persalinan dan memberikan edukasi dalam meningkatkan peran serta keluarga sehingga dapat mengurangi kecemasan ibu bersalin dan menjaga persalinan tetap fisiologis.

\section{DAFTAR PUSTAKA}

1. Kemenkes RI. Survei Demografi dan Kesehatan Indonesia (SDKI) Tahun 2013. Jakarta.2013

2. Dinas Kesehatan Kota Padang. Profil Kesehatan Kota Padang Tahun 2012. Padang. 2013

3. Mariati, U, Agus, Z, Sulin, D, Masrul, Amri Z. Studi Kematian Ibu dan Kematian Bayi di Provinsi Sumatera Barat. Artikel Penelitian. Jurnal Kesehatan Masyarakat Nasional 2011 Vol. 5 no. 6. (diunduh 23 Februari 2015) tersedia darihttp://download.portalgaruda.or g/article.php?article
4. Kemenkes RI. Rencana Aksi Percepatan Penurunan Angka Kematian Ibu di Indonesia. Jakarta. 2013

5. Dolea, C., Abouzahr, C. Global Burden of Obstructed of Labour in the Year 2000, WHO. 2003 (diunduh 12 Maret 2015) tersedia dari

http://www.who.int/healthinfo/stati stics/bod_obstructedlabour.pdf

6. Pairman, Sally. Midwifery: Preparation for Practice 2nd ed. Australia. 2011

7. Brayshaw, E. Senam Hamil \& NIfas : Pedoman Praktis Bidan. Jakarta. 2007

8. Katona, C., Claudia, C., Mary, R. At a Glance Psikiatri Edisi Keempat. Jakarta. 2012

9. Flood, L. P., Brown, S. T., Douglas, C. Womens Evaluation of Intrapartum Nonpharmalogical Pain Relief Methods Used during Labor. The Journal of Perinatal Education. 2001; 10(3):3, 1-8 (Diunduh 23 Februari 2015) tersedia dari https://www.clinicalkey.com/nursin $\mathrm{g} / \# ! /$ content/journal/1-s2.0S1574626715001068

10. Thompson, T., Keogh, E., French, C.C., Davis, R. Anxiety Sensitifity And Pain: Generalisability Across Noxious Stimuli, J. Pain. 2008 (diunduh 23 Februari 2015) tersedia dari

http://research.gold.ac.uk/4294/1/T hompson_et_al_2008.pdf

11. Baesdo, K. Hover, J., Jacobi, F., Low, N., Hofler, M., Wittchen, H. Association Between Generalized Anxiety Levels and Pain in A Community Sample: Evidence For Diagnostic Specificity, J. Anxiety Disorders. 2009; 23(5):684-93 (Diunduh 14 Maret 2015) tersedia darihttp://www.ncbi.nlm.nih.gov/pu bmed/19278819

12. Dahro, A. Psikologi Kebidanan : Analisis Perilaku Wanita Untuk Kesehatan. Jakarta.2012 
13. Adams, S., Eberhard-Gran, M., Es Klid, A. Fear of Childbirth and Duration of Laboour; A Study of Women With Intended Vaginal Delivery, BJOG. 2012; 10, 14710528 (diunduh 15 Maret 2015) tersedia dari http://www.ncbi.nlm.nih.gov/pubm ed/22734617

14. Jensen, Lowdermilk, Bobak, I.M,. Maternity Nursing, 4 th Ed. Mosby. 1995

15. Danuatmaja, B., Meiliasari, M. Persalinan Normal Tanpa Rasa Sakit. Jakarta. 2008

16. Green J, Amis A, Barbara A. Continuous Labor Support. Journal of Perinatal Education. 2007; 16, 25-28 (diunduh 15 Maret 2015) tersedia dari http://www.ncbi.nlm.nih.gov/pmc/a rticles/PMC1948096

17. Sercekus, P., Okumus, H. Fears Associated With Childbirth Among Nulliparous In Turkey, Midwifery. 2009; 25(2), 155-62 (diunduh 15 Maret 2015) tersedia dariwww.ncbi.nlm.nih.gov/pubmed /17600599

18. Taylor. Fundamental of Nursing, The Art and Science of Nursing Care. 4th ed. Philadelphia: Lippincott. 2004, 102:E29

19. Amir, A.M. Kiat-kiat Melahirkan Nyaman Tanpa Rasa Sakit yang Menakutkan. Jogjakarta. 2010

20. BPJS Kesehatan. Panduan Praktis Pelayanan Kebidanan dan Neonatal. Jakarta. 2014

21. Henderson, C. Buku Ajar Konsep Kebidanan. Jakarta. 2006

22. Rukiyah, Y. Konsep Kebidanan. Jakarta. 2011

23. Tursilowati S. Y. Pengaruh Peran Serta Suami Terhadap Tingkat Kecemasan Ibu Hamil dalam Menghadapi Proses Persalinan di Desa Jepat Lor Kecamatan Tayu Kabupaten Pati. Yogyakarta. 2007 